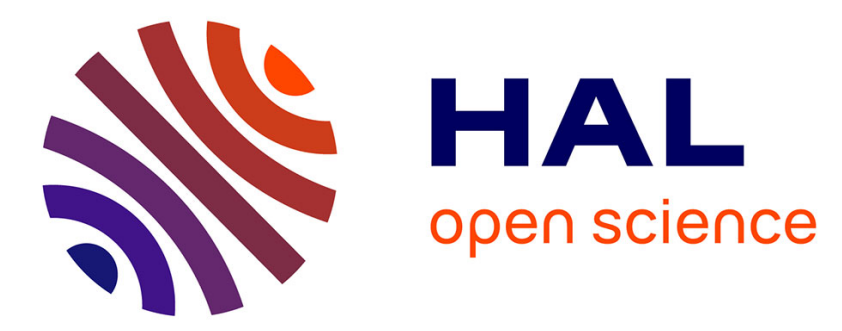

\title{
Mid-latitude lidar observations of planetary waves in the middle atmosphere during the winter of 1981-1982
}

\author{
Alain Hauchecorne, Marie-Lise Chanin
}

\section{To cite this version:}

Alain Hauchecorne, Marie-Lise Chanin. Mid-latitude lidar observations of planetary waves in the middle atmosphere during the winter of 1981-1982. Journal of Geophysical Research. Oceans, 1983, 88 (C6), pp.3843-3850. 10.1029/JC088iC06p03843 . insu-03117580

\section{HAL Id: insu-03117580 \\ https://hal-insu.archives-ouvertes.fr/insu-03117580}

Submitted on 26 Apr 2021

HAL is a multi-disciplinary open access archive for the deposit and dissemination of scientific research documents, whether they are published or not. The documents may come from teaching and research institutions in France or abroad, or from public or private research centers.
L'archive ouverte pluridisciplinaire HAL, est destinée au dépôt et à la diffusion de documents scientifiques de niveau recherche, publiés ou non, émanant des établissements d'enseignement et de recherche français ou étrangers, des laboratoires publics ou privés. 


\section{MID-LATITUDE LIDAR OBSERVATIONS OF PLANETARY WAVES IN THE MIDDLE} ATMOSPHERE DURING THE WINTER OF 1981-1982

A. Hauchecorne and M. L. Chanin

Service d'Aéronomle du C.N.R.S., B.P. 3, 91170, Verrières-Le-Buisson, France

\begin{abstract}
A quasi-continuous survey of the stratospheric and mesospheric temperature was performed, between June 1981 and April 1982, using the lidar station of the observatory of Haute-Provence $\left(44^{\circ} \mathrm{N}, 6^{\circ} \mathrm{E}\right)$. During the period of easterly winds in the lower stratosphere (1.e., from June to September), the variability of the temperature is observed to be very low. As long as prevalling winds are westerlies, from October to March, temperature profiles are continuously perturbed by planetary waves, with a maximum of amplitude in January 1982, before the 'strong minor warning' of the winter. Spectral analyals of the data indicates the presence of a welldefined 18-day wave interpreted as a free Rossby wave and the existence of large perturbations with periods of 25 to 40 days which are tentatively explained a a succession of minor upper stratospheric warmings due to the Interference of the 18 day traveling Rossby wave and a stationary wave.
\end{abstract}

\section{Introduction}

Ground-based 11dar measurements of stratospheric and mesospheric density and temperature have been performed since 1978 at the Observatory of Haute-Provence $\left(44^{\circ} \mathrm{N}, 6^{\circ} \mathrm{E}\right)$. The density is obtalned above $30 \mathrm{~km}$ from the light of a pulsed laser beam backscattered by air molecules, and the temperature is deduced from the density measurements assuming that the atmosphere obeys the Ideal gas law and is in hydrostatic equilibrium, which are standard assumptions [Hauchecorne and Chanin, 1980]. During the period of the two major warmings of the winters 19791980 and 1980-1981 [Labitzke, 1982], lidar profiles showed clearly a stratospheric warming and an associated mesospheric cooling. [Hauchecorne and Chanin, 1981, 1982]. This may be surprising, considering the relatively low latitude of the lidar station, but it should be noticed that because of 1 ts longltude the station is only $25^{\circ}$ to $30^{\circ}$ south of the average position of the center of the polar depression. During the winter of 1980-1981, a variation of the temperature profile with a period of about 20 days was observed and was attributed by the authors to the propagation of planetary waves. To study these planetary waves, a quasi-continuous survey of the nighttime temperature profile has been performed from June 1981 to April 1982. In this paper, the series of 82 profiles obtained during this period is used to study the local temperature variations and their interpretation in terms of planetary waves propagation.

Copyright 1983 by the American Geophysical Union.

Paper number 2C1985.

0148-0227/83/002C-1985\$05.00

\section{Experimental Results}

The main characteristics of the 1idar measurements reported here are, on the one hand, the fact that they are performed locally above the station (with a fixed zenith pointing) and, on the other hand, that they cover with a good height resolution and a very accurate altitude definition the range from 30 to $80 \mathrm{~km}$, which is not not covered by radiosondes, and measured with a degraded resolution by satellites. Then the events that will be referred to will be obviously local, unless mentioned otherwise.

The temperature profiles have been integrated for each night during the whole period of measurements, that $1 \mathrm{~s}$, during 2 to 10 hours depending on weather conditions. The vertical resolution $180.6 \mathrm{~km}$ on the rough data but has been degraded to $4.8 \mathrm{~km}$ to Improve the temperature accuracy. Furthermore, this cholce of temporal and spatial resolutions helps to remove short period fluctuations and short vertical wavelength structures Induced by gravity waves [Chanin and Hauchecorne, 1981].

Seven temperature profiles obtained between September 1981 and Apri1 1982 and representative of typical situations are presented in Figure 1. For each experimental profile are indicated the \pm 1 standard deviation and the Cira (1972) model for the appropriate month and latitude $\left(44^{\circ} \mathrm{N}\right)$. The profile of September 13 (night of September 13-14) is typical of the summer period. It is very close to the C1ra (1972) model and does not present any large perturbation. On November 22 the perturbation of the profile by planetary waves is clearly visible, with a cooling of about $10 \mathrm{~K}$ between 50 and $60 \mathrm{~km}$ and a secondary maximum of temperature at $74 \mathrm{~km}$. The four profiles of January 1982 have been obtalned during the more disturbed period of the winter, just before the 'strong minor warming' of the lower stratosphere occurring at the end of January [Naujokat et al., 1982]. A definite warming becomes noticeable near $50 \mathrm{~km}$ on January 2, then Increases and moves downward to reach a maximum value of $30 \mathrm{~K}$ above the Cira model at $40 \mathrm{~km}$ on January 13. During the same period a strong mesospheric cooling descends from 70 to $58 \mathrm{~km}$. A minimum value $(45 \mathrm{~K}$ below the C1ra) is observed at $62 \mathrm{~km}$ on January 6 .

The perturbation of these three profiles is characterized by a vertical wavelength of about $40 \mathrm{~km}$. This vertical structure is visible both on the density and on the temperature profiles as it is shown on Figure 2 for January 2, 1982. Such vertical wavelengths of about $40-50 \mathrm{~km}$, have already been observed in the winter of 1975-1976 [Offermann et al., 1979] and of 1980-1981 [Hauchecorne and Chanin, 1982]; they seem to be a general feature of the disturbed winter profiles. Owing to these structures the vertical temperature gradient may reach a mean value of $-7 \mathrm{~K}$ $\mathrm{km}^{-1}$ from 50 to $60 \mathrm{~km}$ when the upper strato- 

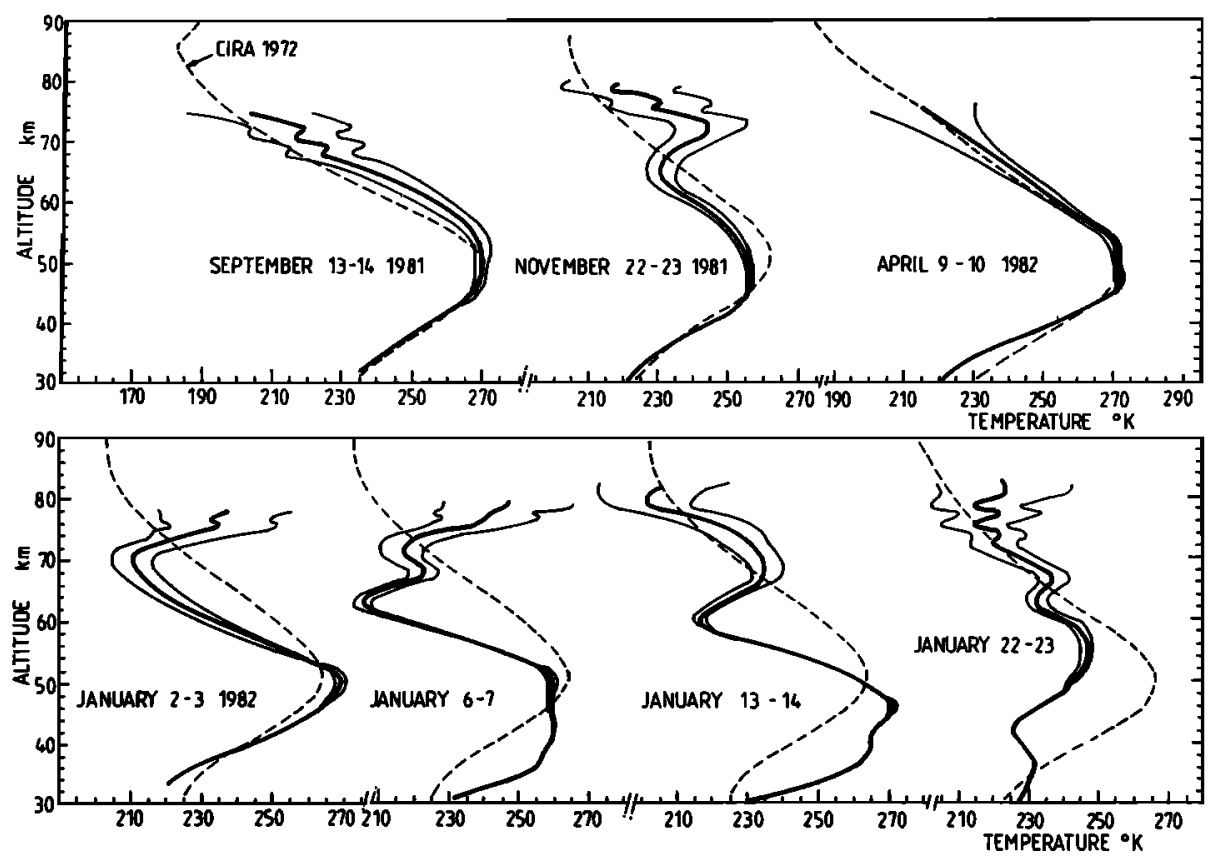

F1g. 1. Series of 7 Lidar temperature profiles obtalned from September 1981 to April 1982. The dotted 11ne represents the C1ra (1972) model for the corresponding month and latitude. The standard deviation $( \pm \sigma)$ is indicated.

sphere is warm and the mesosphere cold. Then, if gravity waves are present, the temperature gradient may be locally amplified up to the adlabatic gradient of $-9.8 \mathrm{~K} \mathrm{~km}^{-1}$, and unstable layers with subsequent turbulent dissipation may then appear in the lower mesosphere.

On January 22 the warming has moved down into the lower stratosphere and is not visible on the 11dar data but appears at the end of January on the radiosonde data both locally and globally, as we will see later. The temperature profile 18 near loothermal from 30 to $80 \mathrm{~km}$ with a very cold stratopause about $20 \mathrm{~K}$ colder than its mean value. The profile of Apri1 9, 1982, shows the return to a sumer quiet situation without any perturbation induced by planetary waves but with a stratosphere colder than Indicated by the C1ra model.

The complete series of temperature profiles obtalned from June 1981 to April 1982 has been

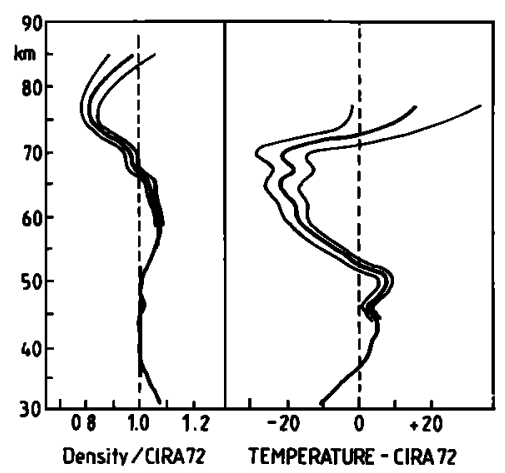

Fig. 2. Density and temperature profiles for the night of January 2-3, 1982, compared with the C1ra (1972) model. The standard deviation 1s indicated. used to study the temporal variation of the stratospheric and mesospheric temperature during these 10 months. The quality and the density of data is not homogenous during that period. To obtain a continuous determination of the temperature and to eliminate possible fluctuations due to the variations in the data accuracy, the temperature at each height level has been approximated and interpolated by use of spline functions with a mean leagt square criterion proportlonal to the standard error of each of the temperature measurements. Temperature profiles have been extended below $30 \mathrm{~km}$, using the radiosonde data of the two nearby stations of Nimes $\left(44^{\circ} \mathrm{N}, 4^{\circ} \mathrm{E}\right)$ and Lyon $\left(46^{\circ} \mathrm{N}, 5^{\circ} \mathrm{E}\right)$.

The time-height section of the temperature from 20 to $70 \mathrm{~km}$ is represented on Figure 3 together with the mean zonal wind from 0 to $30 \mathrm{~km}$ obtained from the data of the same two radiosonde stations. During summertime, from June to September 1981, the temperature 1sopleths are nearly horizontal, corresponding to very little time variation in the temperature profiles. During that period, easterly winds are present in the lower stratosphere, a situation that prevents the propagation of planetary waves into the stratosphere [Charney and Drazin, 1961]. At the beginning of October the change over from easterly to westerly winds occurs in the lower stratosphere. The planetary waves may then propagate into the middle atmosphere, and a succession of large perturbations in the temperature profiles appears in the upper stratosphere and in the mesosphere. The maximum amplitude of these perturbations is observed in January after a period of strong westerly winds and just 'before the 'strong minor warming' of this winter. In February and March the zonal wind is locally easterly or moderately westerly and the amplitude of the perturbations decreases. A 

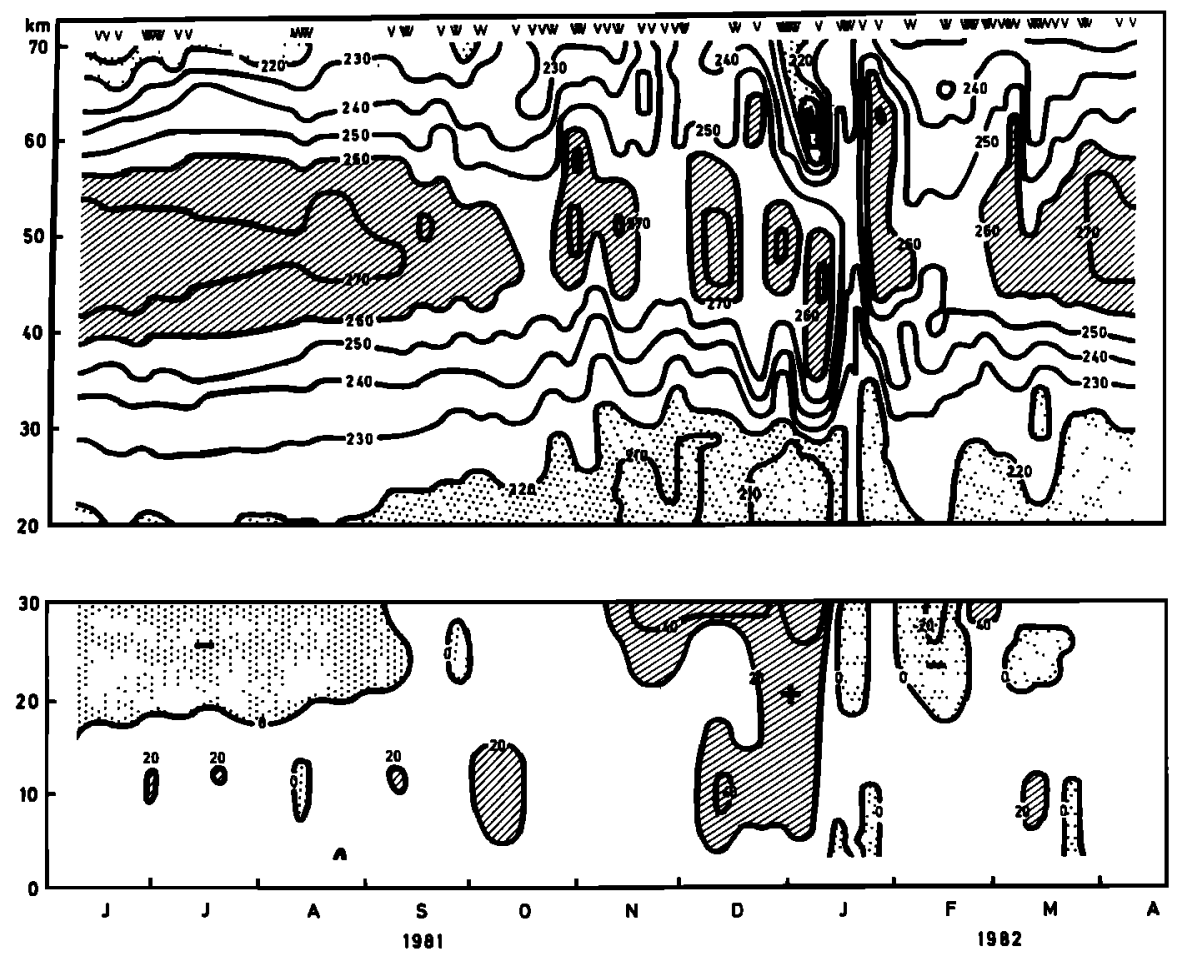

Fig. 3. (Top): T1me helght section of Lidar and radiosonde temperature (R). The contour 11nes are plotted in steps of $10 \mathrm{~K}$. The arrows above Indicate the days when LIdar data were recorded. Shaded areas correspond to temperatures above $260 \mathrm{~K}$, dotted areas to temperatures below $220 \mathrm{~K}$. (Bottom): time helght section of the radiosonde zonal wind (m $\mathrm{s}^{-1}$ ) Westerly winds are $>0$ and represented by the shaded area; easterly winds are $<0$ and represented by dotted area. Contour lines are plotted by steps of $20 \mathrm{~m} \mathrm{~s}^{-1}$.

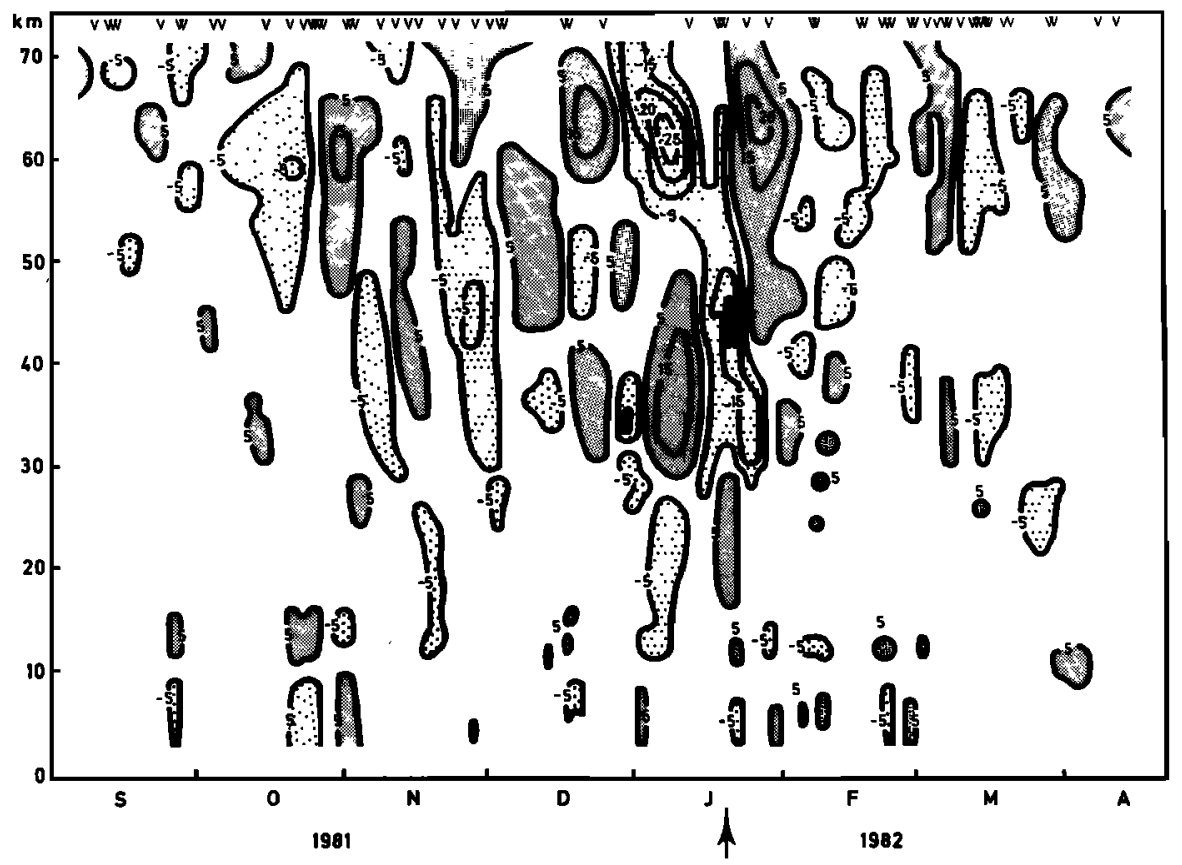

Fig. 4. Time-height section of the temperature deviation from a 45 days running average. Contour lines are plotted in steps of $10 \mathrm{~K}$. Gray areas correspond to a warming. Dotted areas represent a cooling from the average value. The large arrow indicates the time of the strong minor warming. 


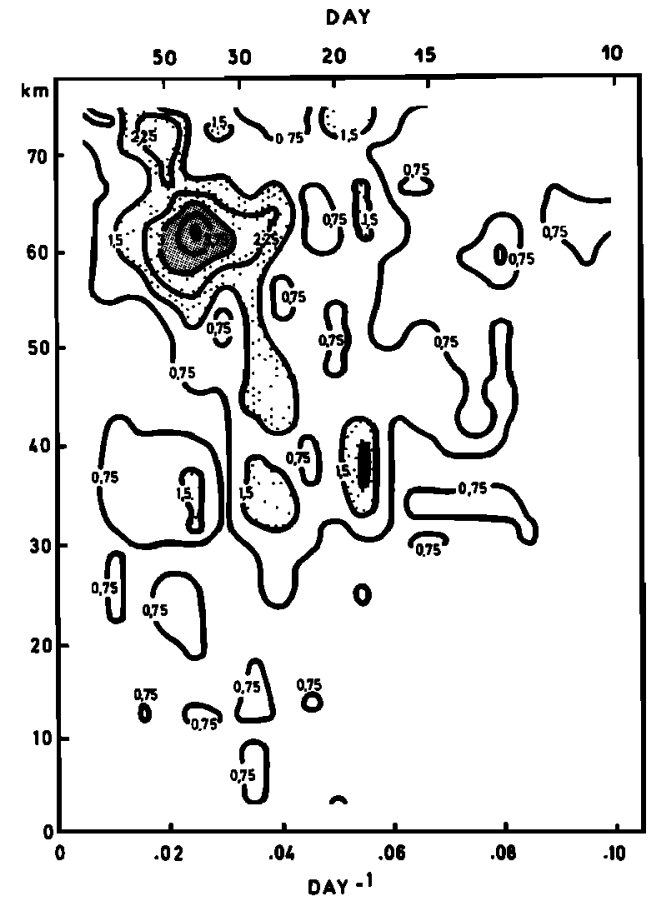

F1g. 5. Frequency-height section of the amplitude of the temperature oscillations (in $\mathrm{K} / 0.005$ day $^{-1}$ ) during the period from September 13, 1981, to March 31,1982 . Contour lines are plotted in steps of $0.75 \mathrm{~K} /\left(0.005\right.$ day $\left.{ }^{-1}\right)$.

return to the quiet summer situation 18 observed at the beginning of April.

\section{Data analysis}

Time analysis of the experimentally observed temperature disturbances has been performed by two complementary analysis. The same type of treatment has also been applied to the pressure values deduced from the density profiles:

1. Temperature : To study the characteristics of the temperature perturbation, the difference between the dally temperature and the mean temperature has been considered. This mean temperature 1s obtalned by applying to the data obtalned for each night of observation a running average with a triangular filter of 45 days half width. These temperature deviations from the mean value are presented in Figure 4 for the period of September 1981 to April 1982. From this representation it appears that a regular succession of coolings and warmings is observed in both the stratosphere and the mesosphere. Furthermore, each warming is associated with a cooling occurring about $20 \mathrm{~km}$ above or below. This corresponds to the $40 \mathrm{~km}$ vertical wavelength already mentioned. Such vertical structures are responsible for the anticorrelation observed in the temperature variation between the upper stratosphere and the lower mesosphere. The periodic variation of these structures does not appear to be due to the propagation of a single planetary wave.

A spectral Fourler analysis of the temperature data has been performed on the data from September 13 to March 31 to study possible

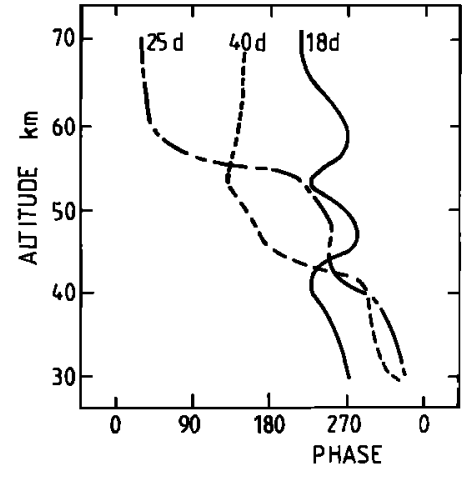

F1g. 6. Phase $\phi$ of the temperature oscillation $T(f, t)$ as a function of height, defined as $T(f, t)=T_{0}(f) \cos \left[2 \pi f\left(t-t_{0}\right)-\phi\right]$ for the three frequencies $f=0.025 \mathrm{day}^{-1}$ (period 40 days), $f=0.040$ day $^{-1} \quad(25$ days $)$ and $f=0.055$ day $^{-1}$ (period 18 days). The origin of time $t_{0}$ is set on September 12,1981 . A negative slope indicates a downward propagation of the phase. The period of analysis is the same as in Fig.5.

periodicities. Figure 5 presents the frequencyheight section of the amplitude of the temperature oscillations. In the stratosphere, three main perlods are observed: 18 days, 25 to 29 days, and 40 days (herein 18D, 25D, and 40D respectively), with a maximum amplitude near 35$40 \mathrm{~km}$ for these three periods. It should be noticed that the stratopause level corresponds to a minimum of amplitude of the temperature variations. In the mesosphere, near $60-65 \mathrm{~km}$, the 18D is still present, but the two longer periods have merged to produce a broad maximum. The maximum amplitudes occur for the 18D in the stratosphere and for the 25 to 40 day periods in the mesosphere. The phase of the 18D, as defined in Figure 6, is nearly constant with altitude, while The phase change of the 25D and 40D indicates a

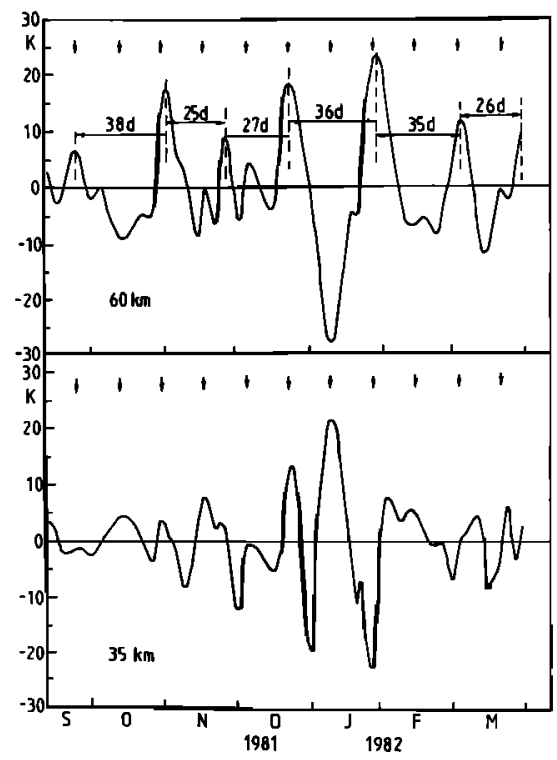

Fig. 7. Deviation from the mean temperature measured at 35 and $60 \mathrm{~km}$. The arrows indicate the dates of the maximum of the $18 \mathrm{D}$ wave computed from the phase shown in Figure 6 . 


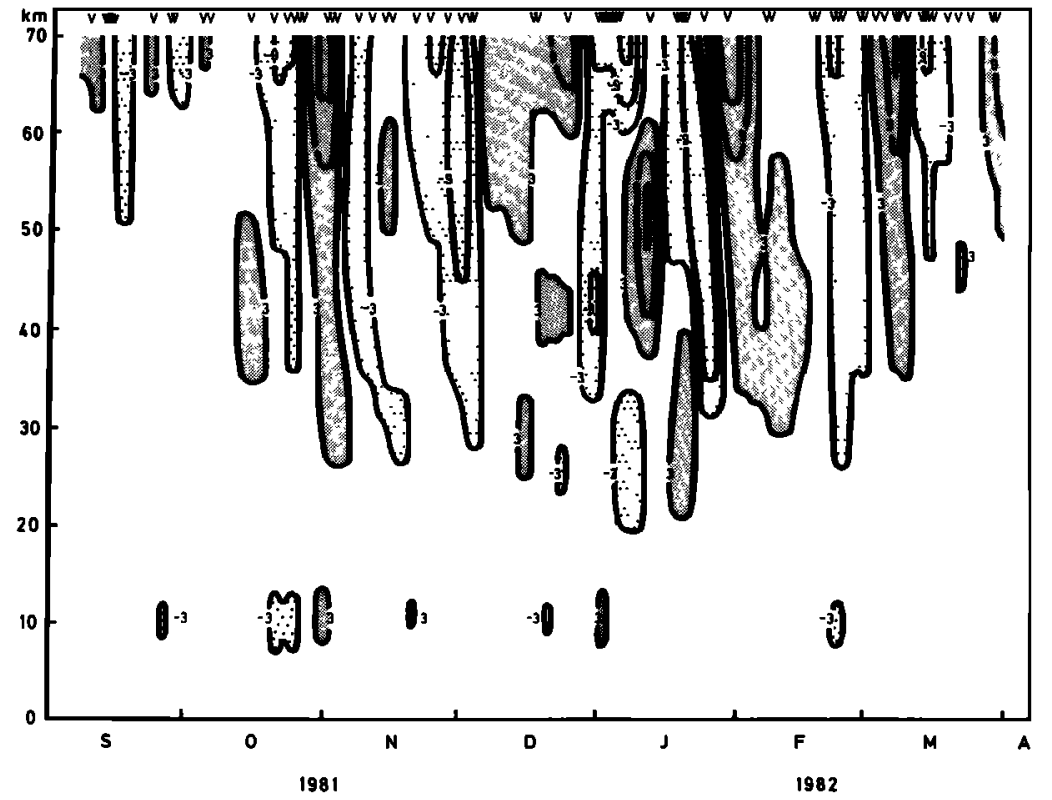

Fig. 8. As in Figure 4 except for the relative difference in percent between the measured pressure and a 45-day running averaged pressure. Contour 11nes are plotted in steps of $6 \%$.

downward propagation. The 18D is probably the same as the 16-day traveling wave observed by Madden and Labitzke [1981] and attributed by them to the $\mathrm{H}_{4}$ Hough mode of a free Rossby wave. As expected from theoretical considerations, its phase is observed to be constant with height. Th1s 18D wave is present in the stratosphere during the whole 6 month period from September 1981 to Apr11 1982. At $35 \mathrm{~km}$ (Figure 7) $1 \mathrm{t}$ is possible to observe each maximum of that wave, except at the end of January, while the strongest warming of the winter is going on. At $60 \mathrm{~km}$, the 18D wave is observed most of the time. On the other hand, the two longer periods are not observed simultanelously, as it can be seen near $60 \mathrm{~km}$ where they dominate the temperature variations. The seven successive maxima of temperature occurring from September 25 to March 31 are separated by $38,25,27,36,35$, and 26 days, respectively. Three of these periods are near 25-27 days, and the three others near 35-40 days. The euccession of these two periods broadens the temporal spectrum and explains the merging of the 25D and 40D in the mesosphere.

2. Pressure. From the radiosonde profiles that extend up to $30 \mathrm{~km}$ and from the lidar density profiles from 30 to $70 \mathrm{~km}$, it is possible to trace the pressure behavior up to $70 \mathrm{~km}$. The deviation of the average daily pressure from the 45 days running average pressure has been evaluated for the period under study (Figure 8). The regular succession of low and high pressures appears clearly above $25 \mathrm{~km}$ with a dominant 18D period and a quasi vertical structure. These features are explained by the fact that the phase of the $18 \mathrm{D}$ temperature wave is constant with altitude, giving a cumulative effect of the temperature perturbations on the pressure perturbations at all levels. On the other hand, the 25D and 40D temperature oscillations are out of phase in the upper stratosphere and lower mesosphere so their contributions to the pressure perturbations are, if not canceled, at least decreased. Thus, the quasi vertical structure observed in the pressure perturbations is easily understood.

A spectral Fourier analysis of the pressure variation confirms the prevalling role of the $18 \mathrm{D}$

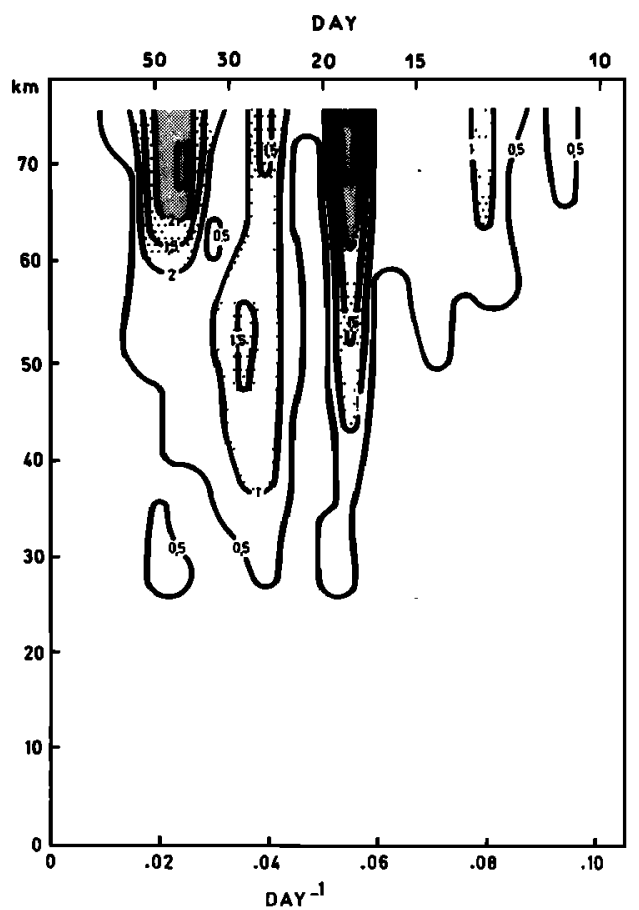

Fig. 9. As in Figure 5 except for the amplitude of the pressure oscillation (1n percent $/ 0.005$ day $^{-1}$ ). Contour lines are plotted in steps of $0.5 \% / 0.005$ day $^{-1}$. 


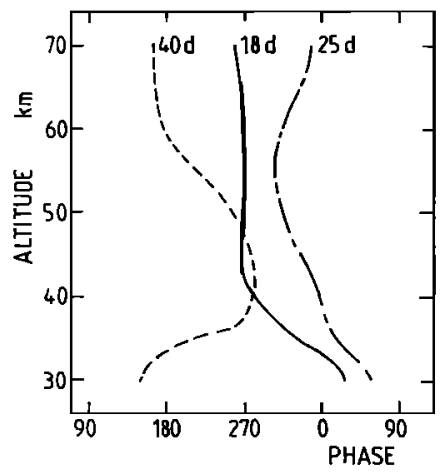

Fig. 10. As in Figure 6 except for the pressure oscillations.

wave as shown in Figure 9. Its period is very well defined ( \pm 1 day), and its amplitude reaches quite high values in the mesosphere $(3 \%$ at $70 \mathrm{~km}$ for the average value over 6 months). The two other larger periods are still present around 25 and 40 days, but with a broader spectrum and a smaller amplitude. The 25D wave appears to be present at all levels above $25 \mathrm{~km}$, while the 40D wave $1 \mathrm{~s}$ only present above $55 \mathrm{~km}$ but with a slightly larger amplitude. The phase of the 18D is constant above $40 \mathrm{~km}$, while its amplitude is increasing, but it decreases slightly with altitude between 30 and $40 \mathrm{~km}$. The phases of the 25D and 40D are decreasing with height between 40 and $60 \mathrm{~km}$, which Indicates a downward propagation as for the temperature perturbations. The phase change of the 40D below $40 \mathrm{~km}$ should not be considered as real, the period not being well defined in this altitude range.

\section{Concluding Remarks}

Lidar observations of stratospheric and mesospheric temperature has allowed us to perform a local and continuous survey of the atmosphere In the altitude range $30-80 \mathrm{~km}$ during the winter of 1981-1982. Such a study performed with a height resolution not available from satellite data has shown detalled structure in the temperature profiles under the influence of planetary waves during the period from October to March when such waves can propagate. On the other hand, during the period of easterly winds, from June to September, the propagation of planetary waves is blocked and then the temperature is observed to be very stable.

The main features observed during the winter are the anticorrelation of the mesospheric and upper stratospheric temperature perturbations (Indicating a vertical wavelength of $40 \mathrm{~km}$ in the temperature profiles) and the succession at constant level of warmings and coolings reaching a large amplitude in January. A spectral analysis of the observed perturbations has shown the presence of three main periods. The 18D wave with a phase constant with height is attributed to the H 4 mode of a free Rossby wave. This represents the first observation of the 18D Rossby wave in this altitude range and suggests the permanent presence of this wave during the winter period. The two longer perlods of about 25 and 40 days are not observed simultaneously, wh1ch may
Indicate the existence of a single variable period. Owing to the large amplitudes associated with these long periods in the mesosphere and to their phase change between the mesosphere and the stratosphere, six main sequences, presenting locally the characteristics of minor warmings, are observed during the winter.

With the usual definition of a 'major warming' [Labitzke, 1982] this specific winter (1981-1982) presented only one 'strong minor warming' at the end of January. As seen by the Lidar, locally at $44^{\circ} \mathrm{N}, 6^{\circ} \mathrm{E}$, six warmings are observed and among them is one of major importance in January. Its temporal relationship with the 'strong minor warming' observed a few days later on a global basis does not appear fortuitous. The existing models are able to explain the vertical structure and the downward propagation of each of the individual warming, whether they are minor or major, by taking into account the interaction between a stationnary wave and the zonal wind [Matsuno, 1971]. To explain the repetitive perturbations in the lower atmosphere (or the so-called vacillations in a zonally averaged flow), Lindzen et al. [1982] developed a theory involving the interference of a stationary wave with a Rossby wave. The recurrent variations reported in this article might also be explained with such an interference, but no model existing today has led to their prediction.

Acknowledgments. The authors wish to thank c. Fehrenbach, Director of the Haute Provence observatory, for his hospitality. They are grateful to all the members of the Lidar group of the Service d'Aéronomie for their help in operating the station and in particular to J. P. Schneider and F. Syda who collected the data. This work was supported by DRET under contract 79-442 and 82-095.

\section{References}

Chanin, M. L., and A. Hauchecorne, L1dar observation of gravity and tidal waves in the middle atmosphere, J. Geophys. Res., 86, 97159721, 1981.

Charney, J. G., and P. G. Drazin, Propagation of planetary scale disturbances from the lower atmosphere into the upper atmosphere, J. Geophys. Res., 66, 83-109, 1961.

Hauchecorne, A., and M. L. Chanin, Density and temperature profiles obtained by 11 dar between 30 and $80 \mathrm{~km}$, Geophys. Res. Lett., 7, 565-568, 1980 .

Hauchecorne, A., and M. L. Chanin, Le Lidar: Un instrument d'étude de la température stratosphérique et mésosphèrique, Notes C. R. Acad. Sc1. Paris, 292, 25-28, 1981 .

Hauchecorne, A., and M. L. Chanin, A mid-latitude ground-based 11dar study of stratospheric warmings and planetary wave propagation, J. Atmos. Terr. Phys., 44, 577-589, 1982.

Labitzke, $K_{\text {., }}$ On the Interannual variability of the middle stratosphere during the Northern winters, J. Meteorol. Soc. Jpn., 60, 124-139, 1982 .

Lindzen, R. S., B. Farrell, and D. Jacqmin, Vacillations due to wave interference: Applications to the atmosphere and to annulus 
experiments, J. Atmos. Sc1., 39, 14-23, 1982

Madden, R. A., and K. Labitzke, A free Rossby wave $1 n$ the troposphere and stratosphere during January 1979, J. Geophys. Res., 86, 1247-1254, 1981 .

Matsuno, T., A dynamic model of the stratospheric sudden warming, J. Atmos. Sc1., 28, 1479-1492, 1971.

Naujokat, B., R. Petzoldt, K. Labitzke and R. Lenschow, The fourth winter of PMP1, 1981/82: A winter with several interesting features,
Be11. Ber1. Wetterkarte, Ber11n, 56/82, 1982. offermann, D., P. Curt1s, J. M. C1smeres, J. Satrustegui, H. Lauche, G. Rose, and $\mathrm{K}$. Petzoldt, Atmospheric temperature structure during the Western European Winter Anomaly Campaign 1975/76, J. Atmos. Terr. Phys., 41, 1051-1062, 1979 .

(Recelved July 29, 1982;

revised November 29, 1982;

accepted December 21, 1982). 